\title{
Optical Coherence Tomography in Urologic Oncology: a Comprehensive Review
}

\author{
J. E. Freund ${ }^{1}$ - M. Buijs ${ }^{1}$ - C. D. Savci-Heijink ${ }^{2}$ - D. M. de Bruin ${ }^{1,3}$ • J. J. M. C. H. de la Rosette ${ }^{4,5} \cdot$ T. G. van Leeuwen ${ }^{3}$. \\ M. P. Laguna ${ }^{4,5}$
}

Accepted: 5 November 2018 / Published online: 23 November 2018

(C) The Author(s) 2018

\begin{abstract}
Introduction Optical coherence tomography (OCT) is being investigated in urologic oncology for optical diagnosis. This comprehensive review analyzes the current state of development of OCT for bladder, upper urinary tract, kidney, prostate, testis, and penis cancer. Also, the potential role of OCT with regard to the current diagnostic pathways is critically appraised to guide future developments. Methods Embase and Pubmed were systematically searched for English and German articles on OCT in humans up to December 2017. Reviews were excluded. Case reports were excluded, unless they presented a landmark in the development of OCT. Results Out of 878 articles, 17 relevant articles on bladder, seven on kidney, five on upper urinary tract, four on prostate, and two on penile cancer were included. In these organs, in vivo OCT imaging is feasible with potential for qualitative and quantitative diagnosis, grading and staging in specific organs. The development of OCT has reached IDEAL stage $2 \mathrm{~b}$ with $2 \mathrm{~b}$ level of evidence. Relevant articles on testis cancer were lacking.

Conclusion OCT allows for non- or minimally invasive cancer diagnosis in the bladder, upper urinary tract, kidney, prostate, and penis. In some organs, OCT also may enable histologic grade and stage prediction. However, the current evidence is still at an exploratory level. With regard to the potential additional value of OCT in comparison to the current diagnostic pathways, OCT could become a diagnostic replacement or add-on test for urothelial carcinoma, penile carcinoma, and renal masses. Further research in these conditions should be encouraged.
\end{abstract}

Keywords Optical coherence tomography $\cdot$ Urothelial carcinoma $\cdot$ Prostate carcinoma $\cdot$ Kidney cancer $\cdot$ Penile carcinoma $\cdot$ Testis carcinoma

\section{Introduction}

In quest of optimizing diagnostic pathways, new imaging modalities are constantly developed. Among them, optical

This article is part of the Topical Collection on Imaging

J. E. Freund

j.e.freund@amc.uva.nl

1 Department of Urology, Amsterdam UMC, University of Amsterdam, Amsterdam, The Netherlands

2 Department of Pathology, Amsterdam UMC, University of Amsterdam, Amsterdam, The Netherlands

3 Department of Biomedical Engineering \& Physics, Amsterdam UMC, University of Amsterdam, Amsterdam, The Netherlands

4 Department of Urology, Istanbul Medipol University, Istanbul, Turkey

5 Amsterdam UMC, University of Amsterdam, Amsterdam, The Netherlands imaging is riding on the crest of a wave with a good example on the rising interest in optical coherence tomography (OCT).

OCT, also called the optical analogue of ultrasound imaging, facilitates in vivo high-resolution cross-sectional imaging of tissues. In contrast to ultrasound imaging, which uses time of flight measurements for depth ranging, OCT depth information is obtained by low-coherence interferometry, in which the depth resolution is determined by the coherence length of the broadband light source. The contrast in the OCT depth scans is based on differences in backscattering properties of the tissue under study. These contrast-based reflection profiles are called amplitude scans (A-scans). As the amplitude of the backscattered light is related to tissue-specific optical properties, tissue-distinctive A-scans are yielded. Adjacent A-scans can be merged to create two-dimensional scale cross-sectional OCT brightness scans (B-scans), (Fig. 1). Based on these Bscans, OCT systems can generate three-dimensional image sets for improved spatial insight. 


\section{From A-scan to B-scan to 3D-scan}

a

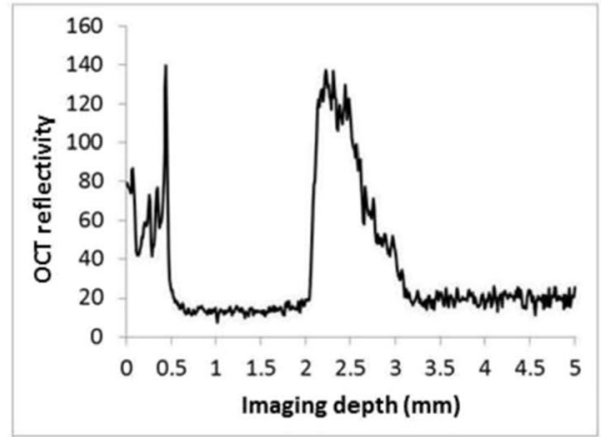

b

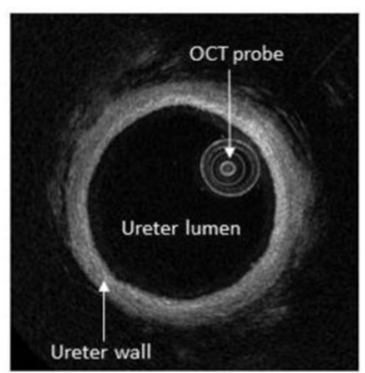

C

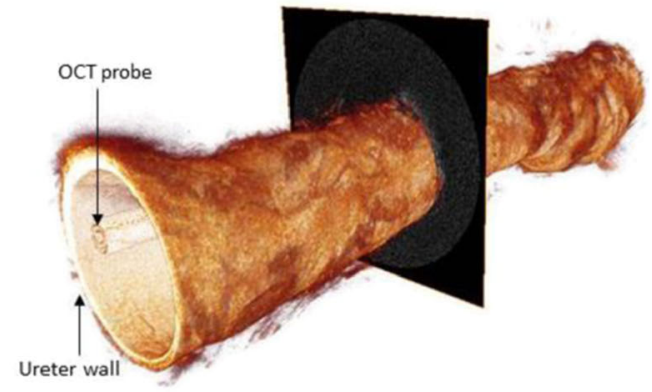

Fig. 1 From amplitude scan to brightness scan to 3D scan. Legend: a amplitude scan of OCT, b brightness scan of OCT, $\mathbf{c}$ three-dimensional scan of OCT

In general, OCT systems that utilize near-infrared light have an axial resolution of $\sim 10 \mu \mathrm{m}$. Therewith, OCT fills the gap on the resolution scale between confocal microscopy and ultrasound imaging. The amplitude of the backscattered light reduces exponentially with tissue depth. This limits the OCT imaging range to approximately $2-3 \mathrm{~mm}$ tissue depth.

At present, OCT has become a valuable tool for non- or minimally invasive imaging in ophthalmology and cardiology due to its non-contact mode imaging capabilities and image resolution. OCT seems also ideal for imaging of epithelial tumors as most of them arise within the first millimeters of the superficial layers [1]. Furthermore, carcinogenesis alters the nuclear morphology, which changes the optical properties of malignant tissue. This leads to differences in OCT reflection profiles between benign and malignant tissue [2]. Hence, these OCT reflection profiles allow for qualitative and quantitative assessment for tumor diagnosis. Tissue layers can be delineated visually on OCT B-scans. Also, quantitative analyses of OCT images have been explored. Statistical, structural, and spectral texture analyses of OCT images have been applied for computer-aided tumor detection [3, 4]. Quantification of OCT signal depolarization may also serve for automated diagnosis [5, 6]. Furthermore, the decrease in OCT signal with tissue depth, quantified by the attenuation coefficient $\left(\mu_{\mathrm{OCT}}, \mathrm{mm}^{-1}\right)$, has been explored for cancer diagnosis and histologic grading [7-9].

Currently, three different types of devices, interfaced to OCT systems, have been investigated for urologic applications: (1) handheld forward-looking devices, (2) forwardlooking probes of $>3 \mathrm{Fr}$, and (3) sideward-looking probes of $<3$ Fr. The handheld device is used for extracorporeal en face OCT imaging of epithelial tissue. Forward-looking probes are used for en face OCT imaging of tissue during endoscopic or laparoscopic procedures. Sideward-looking probes, developed for cardiovascular imaging, are compatible with flexible ureteroscopes and 18-G needles, and hence enable ureterorenoscopic or needle-based imaging of soft tissues. Characteristic for the sideward-looking probes is the automated rotary pullback system that enables helical imaging of the peripheral surrounding during the pullback. The availability of different types of OCT devices and the variety in OCT image assessment methods facilitate possibilities to optimize the current diagnostic pathways in urologic oncology.

The aim of this comprehensive review is to provide an overview of the current state of development of OCT in urologic oncology. Secondly, the diagnostic and clinical practical value of OCT for the diagnosis of malignancies in the bladder, upper urinary tract, kidneys, prostate, testis, and penis are discussed. The assessment of the current state of development and the potential role of OCT is essential to guide further developments towards clinical implementation into urologic oncology.

\section{Materials and Methods}

A systematic search of the literature was conducted in PubMed and Embase for each urologic cancer with key terms to identify English and German original articles on OCT in human studies until December 2017 (Appendix A). All original articles on ex vivo or in vivo human studies were included. Animal studies were excluded. In case of overlapping study populations from the same group, only the most recent article was included. Reviews were excluded. Case reports were also excluded, unless the findings presented a landmark in the development of OCT.

Data extraction was performed by two independent reviewers (J.F., D.d.B.). In case of disagreement, consensus was reached with a third reviewer (M.B.). The results of the evidence acquisition are illustrated in Appendix A. 


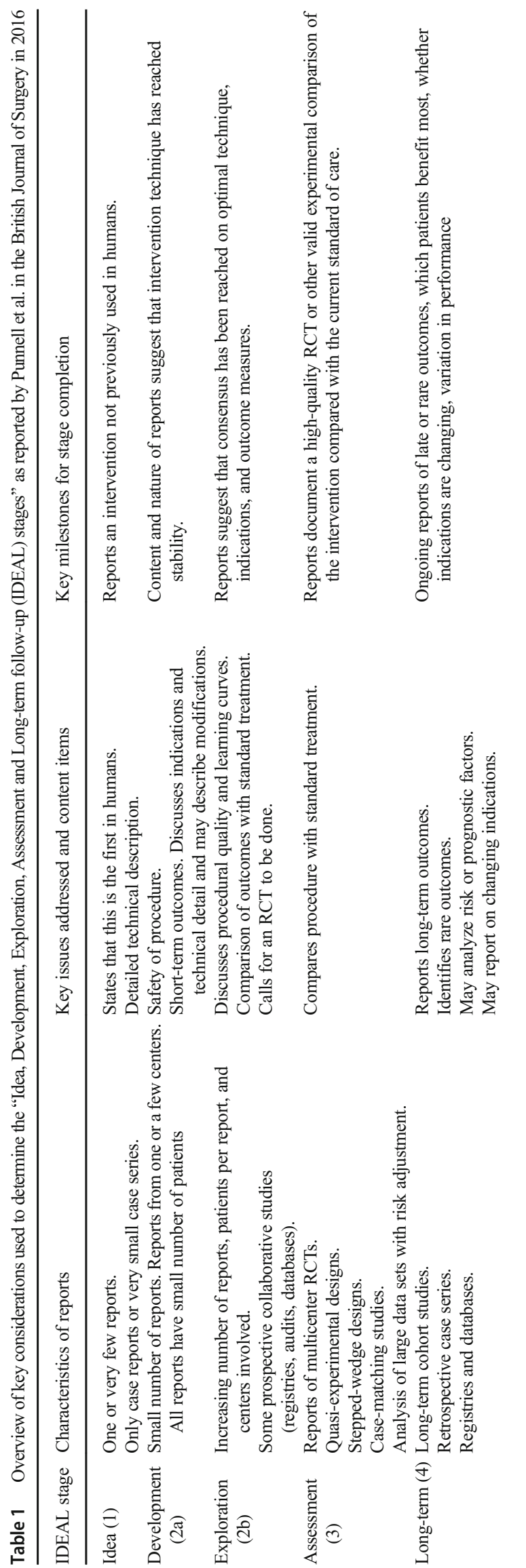

The level of evidence (LoE) of the included articles was assessed according to the Oxford Centre for Evidence-based Medicine model [10]. Furthermore, the articles were rated according to the IDEAL recommendations to assess the current state of development [11]. Table 1 illustrates the key considerations to determine the IDEAL stage as reported by Pennell et al. [11].

We did not proceed to a systematic review because of the explorative stage of OCT in urology.

\section{Results}

\section{Bladder Cancer}

Bladder cancer (BC) is ranked among the ten most common cancers worldwide [12]. BC arises in $90 \%$ of the cases from the urothelium. Normal urothelium consists of a wellorganized layer of 2-7 transitional cells with a mean layer thickness of $61 \mu \mathrm{m}$ [13]. The urothelium is demarcated from the underlying lamina propria (LP) by the basement membrane. Underneath the LP lies the muscularis propria (MP). In a normal condition, all tissue layers of the bladder are regularly structured and well organized [14, 15]. Malignant urothelium, however, has a tendency towards disorganization of the microarchitecture and the possibility of invasiveness into the underlying tissue layers.

Histopathological assessment of BC is fundamental for diagnosis, risk-stratification, and prognosis. However, the clinical practical value and the diagnostic accuracy of transurethral biopsies or resection are limited [16]. Especially, the identification of carcinoma in situ (CIS) is challenging with white light cystoscopy [12]. Furthermore, in the absence of transurethral resection or biopsies, the diagnostic pathway for $\mathrm{BC}$ lacks histologic certitude for a definite diagnosis. This hampers direct outpatient treatment of low-risk tumors with active surveillance or laser fulguration. Therefore, new optical imaging techniques such as OCT may lead to an improvement of the current diagnostic pathway and personalized care for $\mathrm{BC}$.

Twenty relevant articles on OCT in $\mathrm{BC}$ were identified in the systematic search, of which two were overlapping study populations (Table 2) [1, 3, 5-7, 17-29].

OCT imaging of human urologic tissue was performed for the first time in an ex vivo setting in 1997 [25]. Shortly thereafter, the first in vivo OCT imaging was performed during cystoscopy with a forward-looking OCT probe. Visual delineation of tissue layers with OCT was feasible. The size of the cellular structures on OCT images corresponded with histologic morphometry of the resection specimen [1]. Further studies reaffirmed the following OCT characteristics of bladder tissue: normal urothelium is seen as a thin horizontal layer of uniform low signal intensity $[6,17,21,22,26-29]$. The LP 


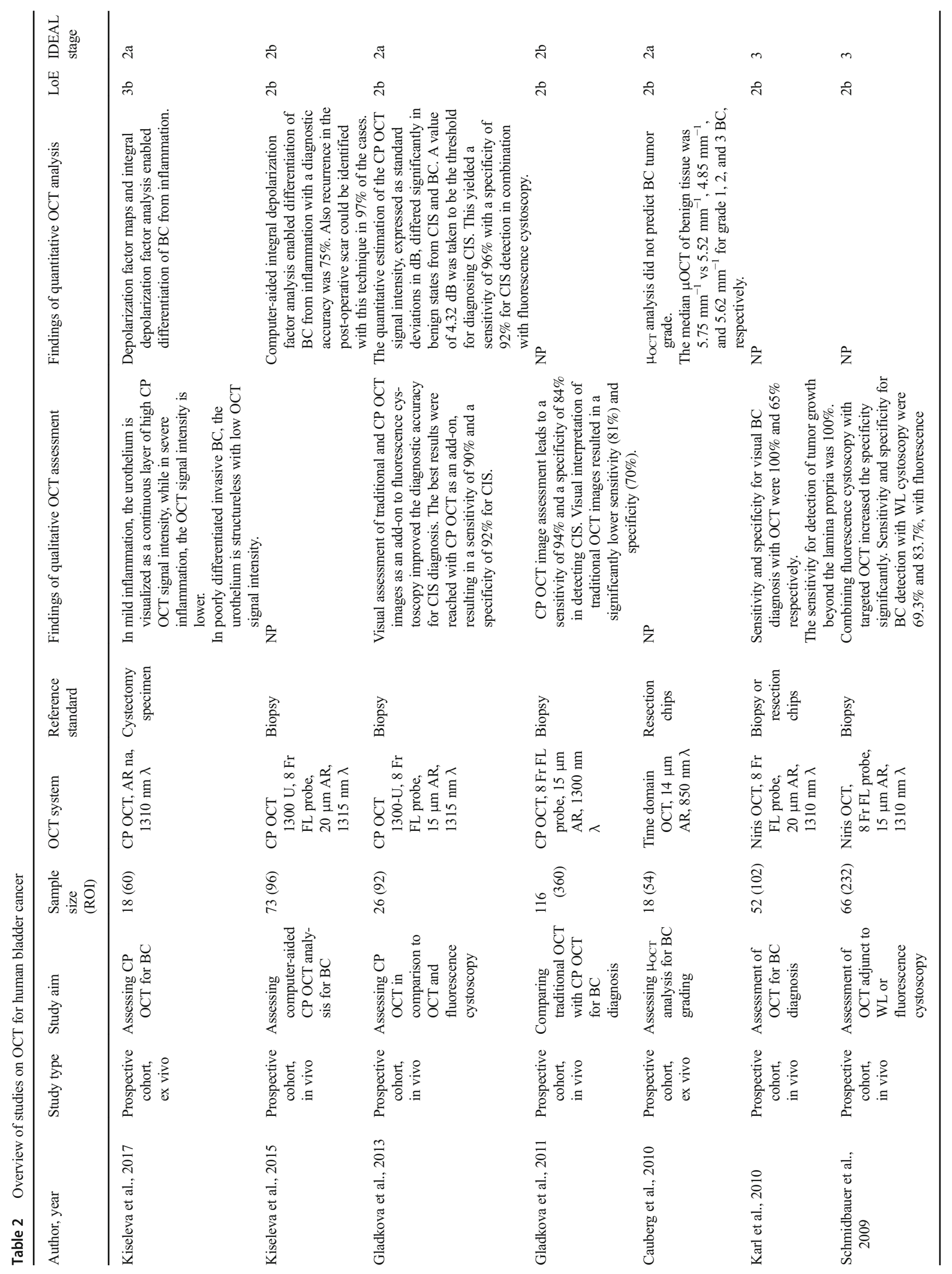




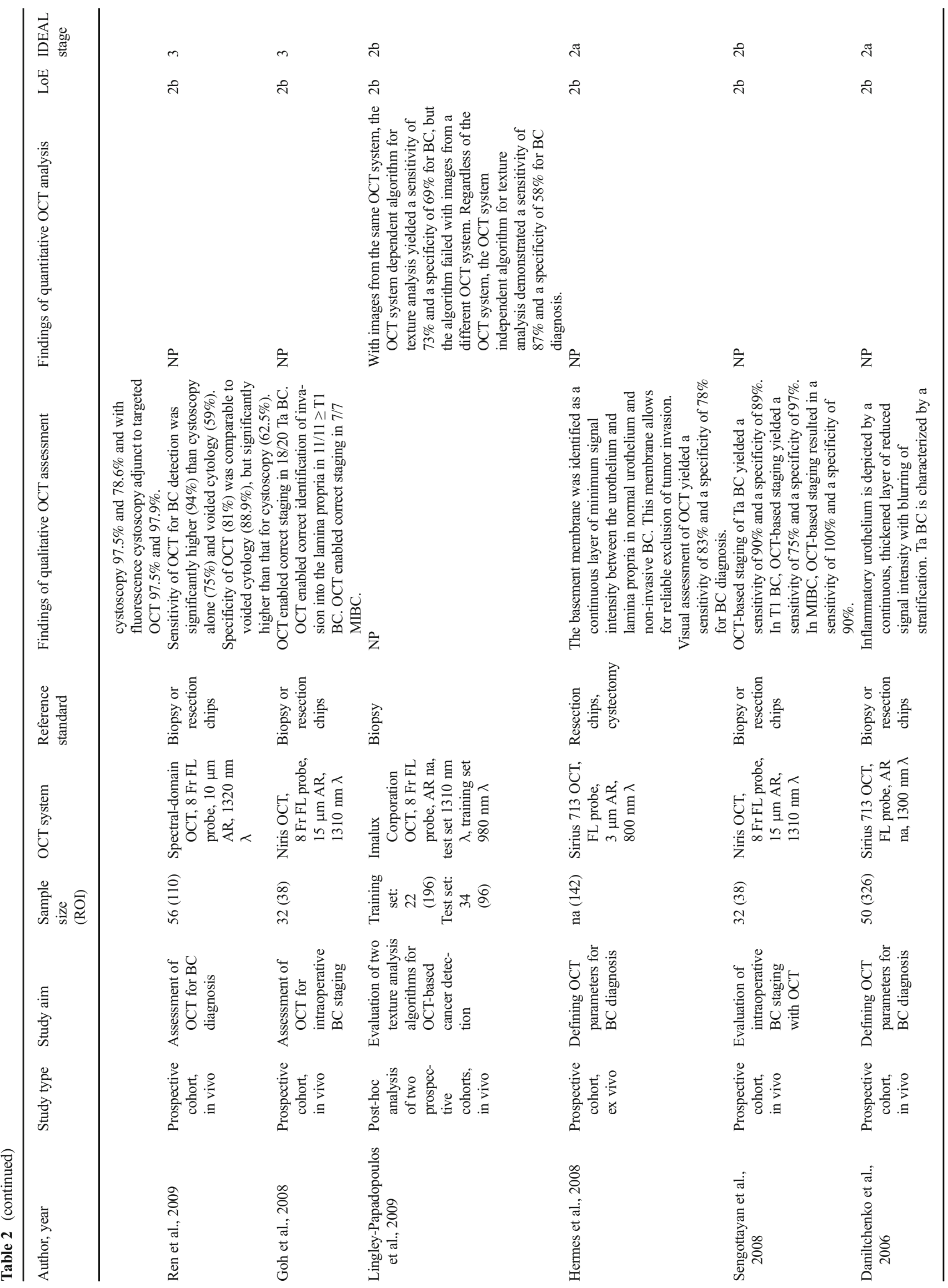




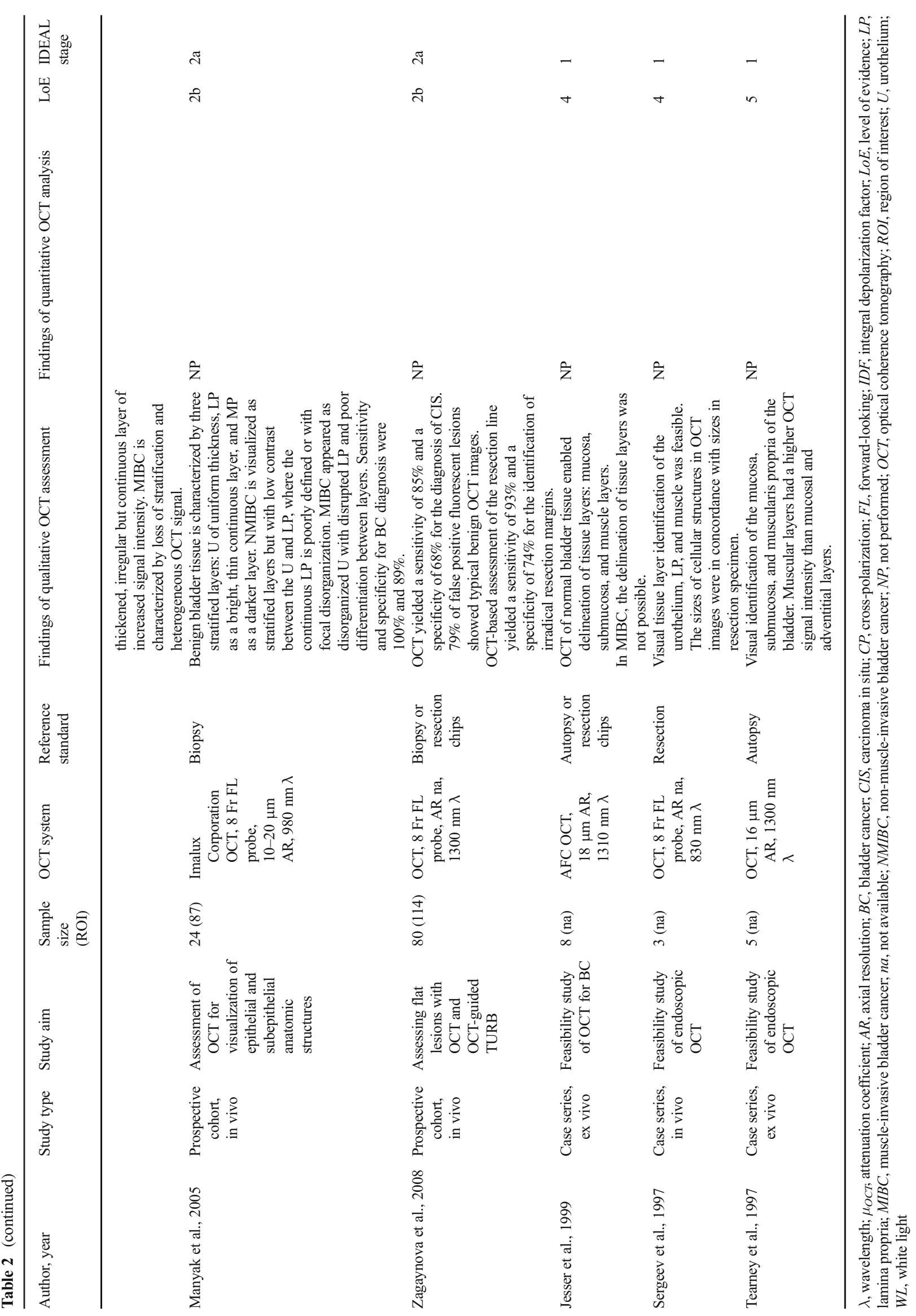


causes more scattering and thus appears as a brighter horizontal underlying layer with OCT. Due to the abrupt change of optical properties between the urothelium and the LP, a clear demarcation between the tissue layers can be seen in OCT images (Fig. 2). Between these two layers, the basement membrane may be visualized with OCT, enhancing the demarcation between the urothelium and the LP. Interruption of this demarcation line in OCT images is a characteristic for tumor invasion (Fig. 2) [21, 28]. In OCT images of muscle-invasive $\mathrm{BC}$, the layer of the LP is irregular or disrupted towards the MP [17, 21, 26, 27]. Regardless of invasiveness, BC is usually visible as an irregular, thickened layer of heterogeneous signal intensity in OCT images. The visualization of CIS by means of OCT is difficult. In OCT images, CIS and inflammation are characterized by heterogeneous signal intensity of the unbroadened urothelium, causing a reduced contrast with the untouched LP [27].

Several studies have described the use of OCT as adjunct to white light cystoscopy for bladder cancer diagnosis and staging $[17,20,26,27,29]$. In these mainly small cohorts, the sensitivity and specificity of OCT during cystoscopy for BC diagnosis ranged from 75 to $100 \%$ and 65 to $89 \%$, respectively $[6,17,21,22,26]$. OCT adjunct to cystoscopy resulted in an increase in sensitivity and specificity of $19 \%$ for BC diagnosis in comparison to WL cystoscopy [19]. Schmidbauer et al. and Zagaynova et al. also illustrated an increase in the diagnostic accuracy when using OCT in conjunction with photodynamic diagnostics $[17,20]$. For the diagnosis of non-muscle-invasive $\mathrm{BC}$, Goh et al. reported a sensitivity of $75-90 \%$ and a specificity of $89 \%$ with OCT. For the diagnosis of BC invasion,
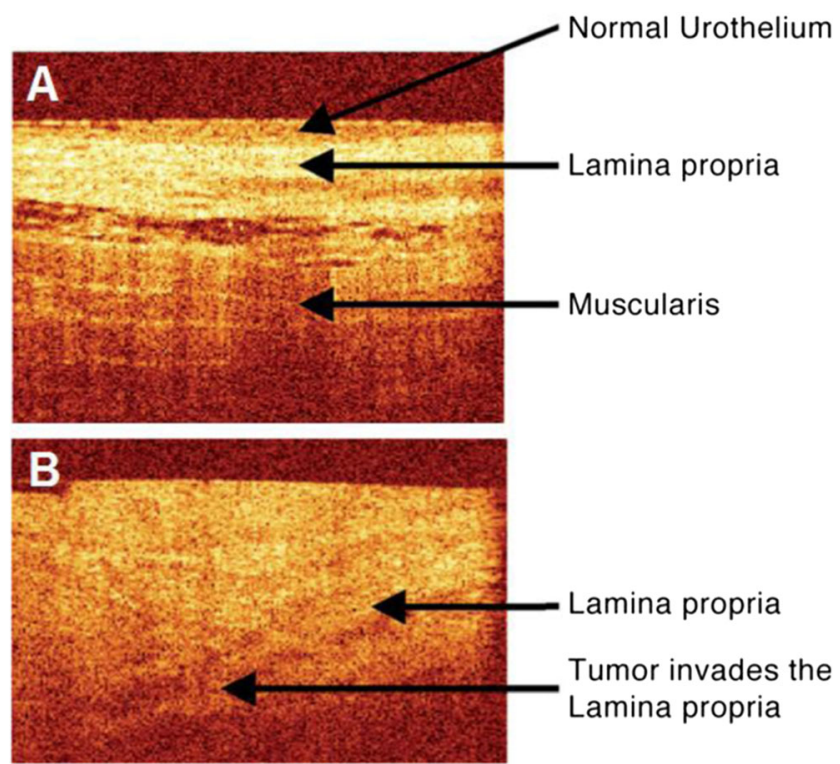

Fig. 2 OCT scans of bladder cancer [published by Karl et al. in Eur. J. Med. Res. 2010]. Legend: a OCT brightness scan of normal bladder tissue with delineation of tissue layers, b OCT brightness scan of muscleinvasive urothelial carcinoma. Note that tissue layer identification is not possible due to the invasive character of the urothelial carcinoma sensitivities of $100 \%$ and a specificity of $77-90 \%$ were reported for OCT [17, 29].

Besides qualitative assessment, quantitative analysis of changes in OCT cross-polarization backscattering and integral depolarization factor reached a diagnostic accuracy for BC of $75 \%[5,6,23]$. However, quantitative analysis of the $\mu_{\mathrm{OCT}}$ was not feasible in ex vivo for BC diagnosis and grading. The negative results were thought to be caused by the ex vivo study design [7].

In summary, OCT enables qualitative $\mathrm{BC}$ diagnosis and staging but the current state of development is at IDEAL stage $2 \mathrm{~b}$ with evidence limited to level $2 \mathrm{~b}$. Crosspolarization OCT may enable quantitative $\mathrm{BC}$ diagnosis and other quantitative OCT-based analyses should be explored further. As such, OCT could facilitate a real-time outpatient evaluation of suspicious bladder lesions without transurethral resection for histopathology. However, qualitative OCT-based diagnosis of CIS was not possible due to the similarity with inflammation. Future research should be stimulated to reaffirm the clinical potential and to advance quantitative algorithms for BC diagnosis. Yet, the lack of a commercially available forward-looking OCT probe may be a threat to further development.

\section{Upper Urinary Tract Cancer}

Upper urinary tract cancers are almost exclusively upper tract urothelial carcinomas (UTUC). It is a rare disease with an incidence of about 2 cases per 100,000 people [30]. The histopathology of benign and malignant tissue in the upper urinary is highly similar to bladder urothelium. The normal intraluminal lining of the upper urinary tract consists of a few well-organized urothelial cell layers. The LP is clearly demarcated on each site by either the urothelium or the smooth muscle layer. Malignant urothelium is characterized by a tendency towards disorganization of urothelial cells and undefined tissue borders in case of invasiveness [14].

Ureteroscopic tissue biopsies are essential for the diagnostic process. Tumor grade and stage are decisive factors in the choice between radical nephroureterectomy (RNU) and kidney-sparing treatment [30]. However, ureteroscopic biopsy in the upper urinary tract is challenging due to the restricted range of motion of the instruments, the risk of complications, and the restricted sampling. Together with interpretation problems due to the limited biopsy volume, fragmentation and inter-observer variability, up to $20 \%$ of upper urinary tract biopsies are inconclusive. This results in limited reliability of UTUC grading and staging by ureteroscopic biopsies [31, 32].

Literature regarding the use of OCT in the upper tract is scarce. The systematic search yielded 6 relevant articles, of which 2 were overlapping studies [9, 25, 33-35]. Moreover, two studies primarily investigated the use of OCT for renal cancer diagnostics $[34,35]$. An additional article that 


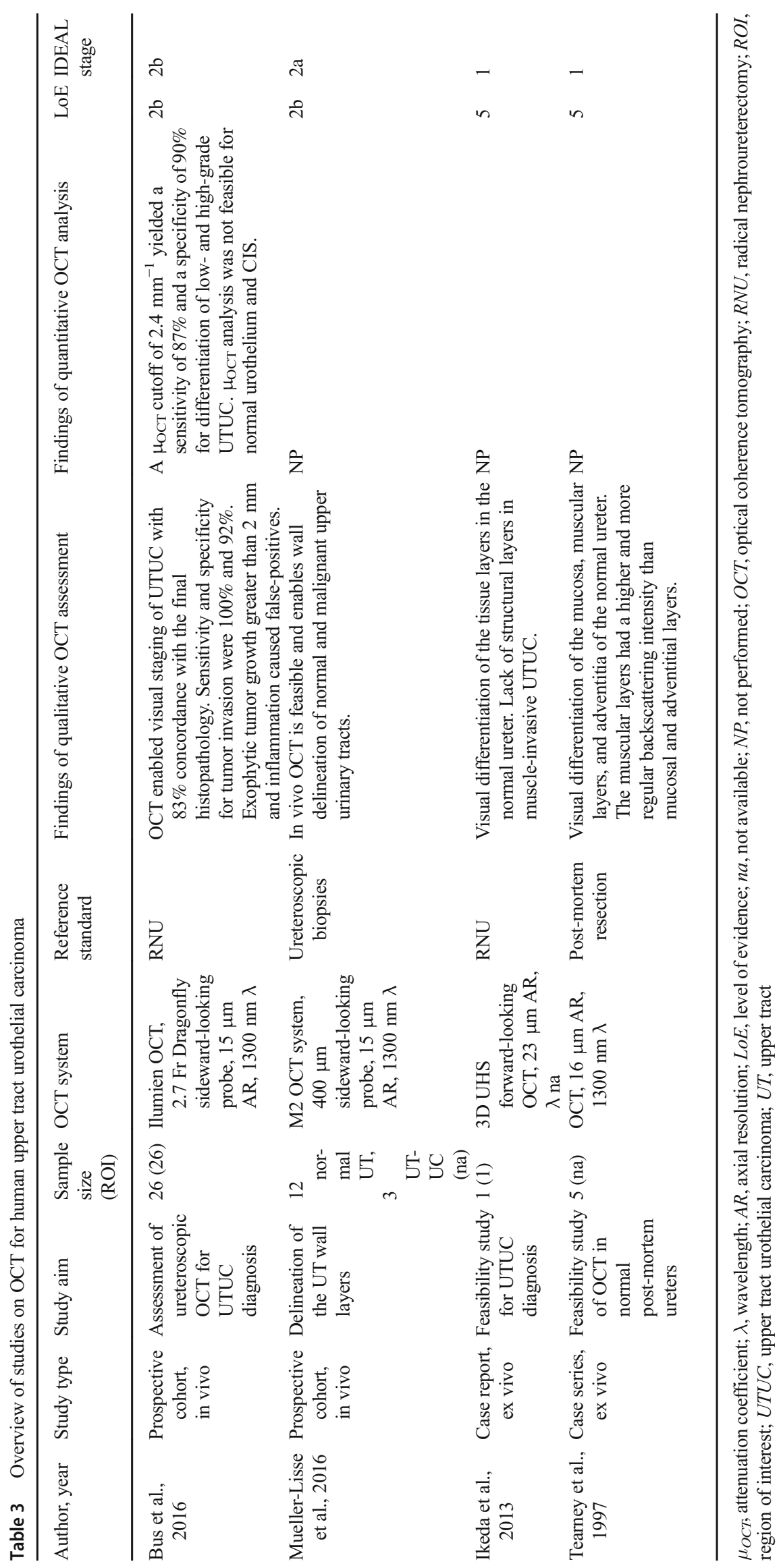


Fig. 3 OCT brightness scans \& histopathology of UTUC and penile cancer. Legend: A1 +2) Intraluminal OCT brightness scan $\&$ histopathology of a stage $\mathrm{pTa}$ UTUC with a continuous lamina propria (indicated by arrows in OCT brightness scan). $\mathrm{B} 1+2$ ) Intraluminal OCT brightness scan \& histopathology of a pT2 UTUC with a disrupted lamina propria \& heterogeneous backscattering (indicated by an arrow in OCT brightness scan). $\mathrm{C} 1+2$ ) OCT brightness scan \& histopathology of a penile intraepithelial neoplasia with broadened epithelium (indicated by a double arrow in OCT brightness scan) adjacent to normal epithelium (single arrow)
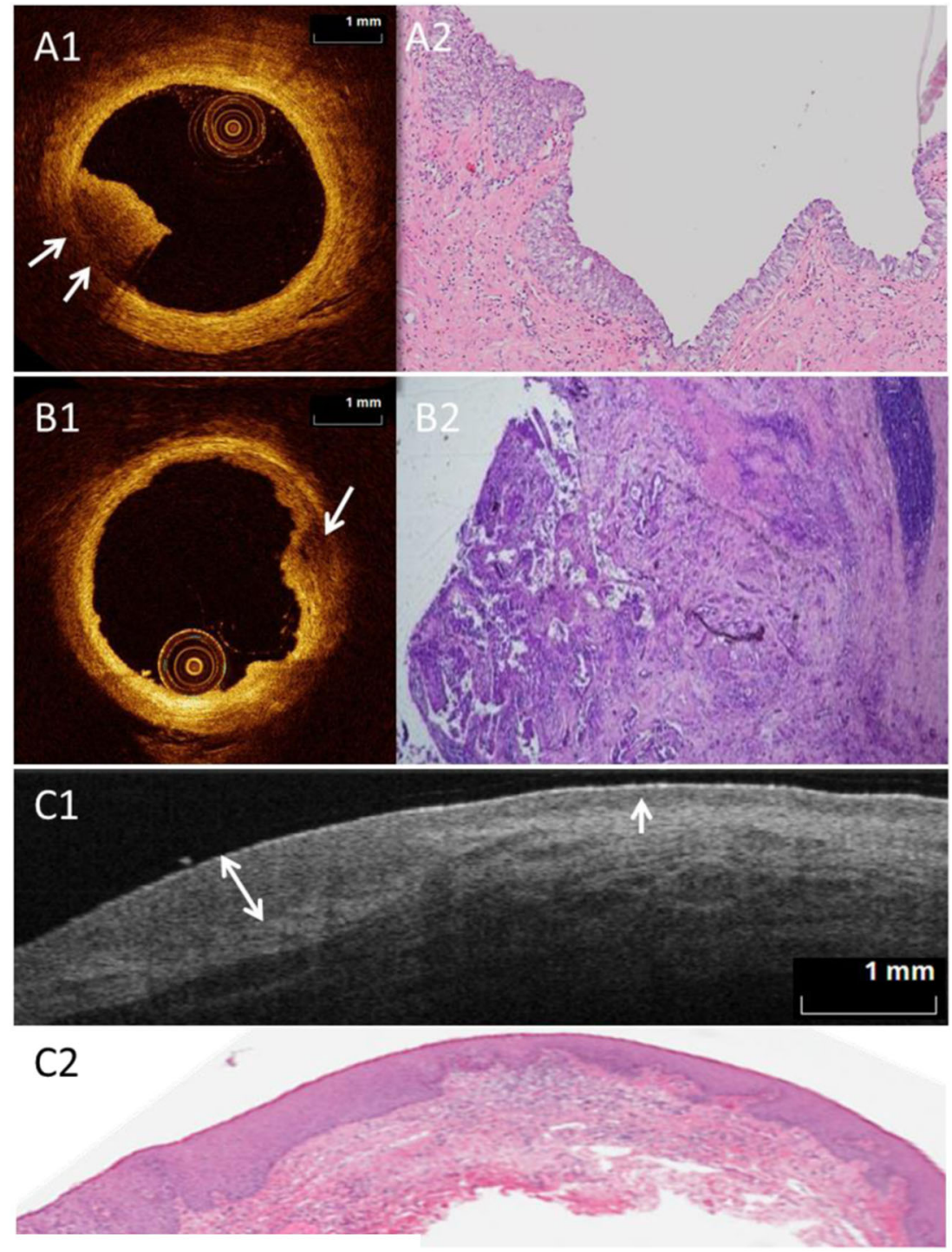

investigated OCT in normal UT and UTUC was identified by snowballing [36]. The studies that primarily investigated OCT for UTUC are presented in Table 3.

Already in 1997, ex vivo OCT imaging of the upper urinary tract was investigated [25]. Visual tissue layer identification, as observed in the bladder, was confirmed for normal UT and invasive UTUC [33-36].

The development the sideward-looking OCT probes for intravascular imaging has enabled the use of OCT during ureterorenoscopy $[9,36]$. In this way, real-time endoluminal OCT imaging enables visualization of UTUC and the layered tissue anatomy (Fig. 3). Interruption and loss of anatomical layers are characteristic for invasive UTUC. Bus et al. reported a concordance of $83 \%$ for qualitative tumor staging on OCT images in comparison to the RNU histopathology [9]. In the same study, quantitative $\mu_{\mathrm{OCT}}$ analysis leads to differentiation between low-grade and high-grade UTUC. A $\mu_{\mathrm{OCT}}$ cutoff value of $2.4 \mathrm{~mm}^{-1}$ for the differentiation of low- and high-grade UTUC resulted in a sensitivity of $87 \%$ and a specificity of $90 \%$. However, $\mu_{\text {OCт }}$ analysis was not feasible for normal urothelium and CIS. The infeasibility to measure the change of OCT signal with imaging depth might be caused by the thinness of the urothelial layer in these cases. Moreover, tumor staging was restricted to exophytic tumors of $<2 \mathrm{~mm}$ depth due to the limited OCT imaging range [9]. Another drawback was that the sideward-looking probe requires a parallel position with the tissue of interest for OCT imaging. This may impair the visualization of the calyceal cavities with OCT. Nevertheless, this LoE $2 b$ study at IDEAL stage $2 b$ showed that OCT has a high diagnostic accuracy and clinical potential for perioperative UTUC grading and staging [9]. Future research should be warranted. The development of a combined sideward- and forward-looking probe may overcome current technical limitations in the application of the technique for UTUC diagnosis. 


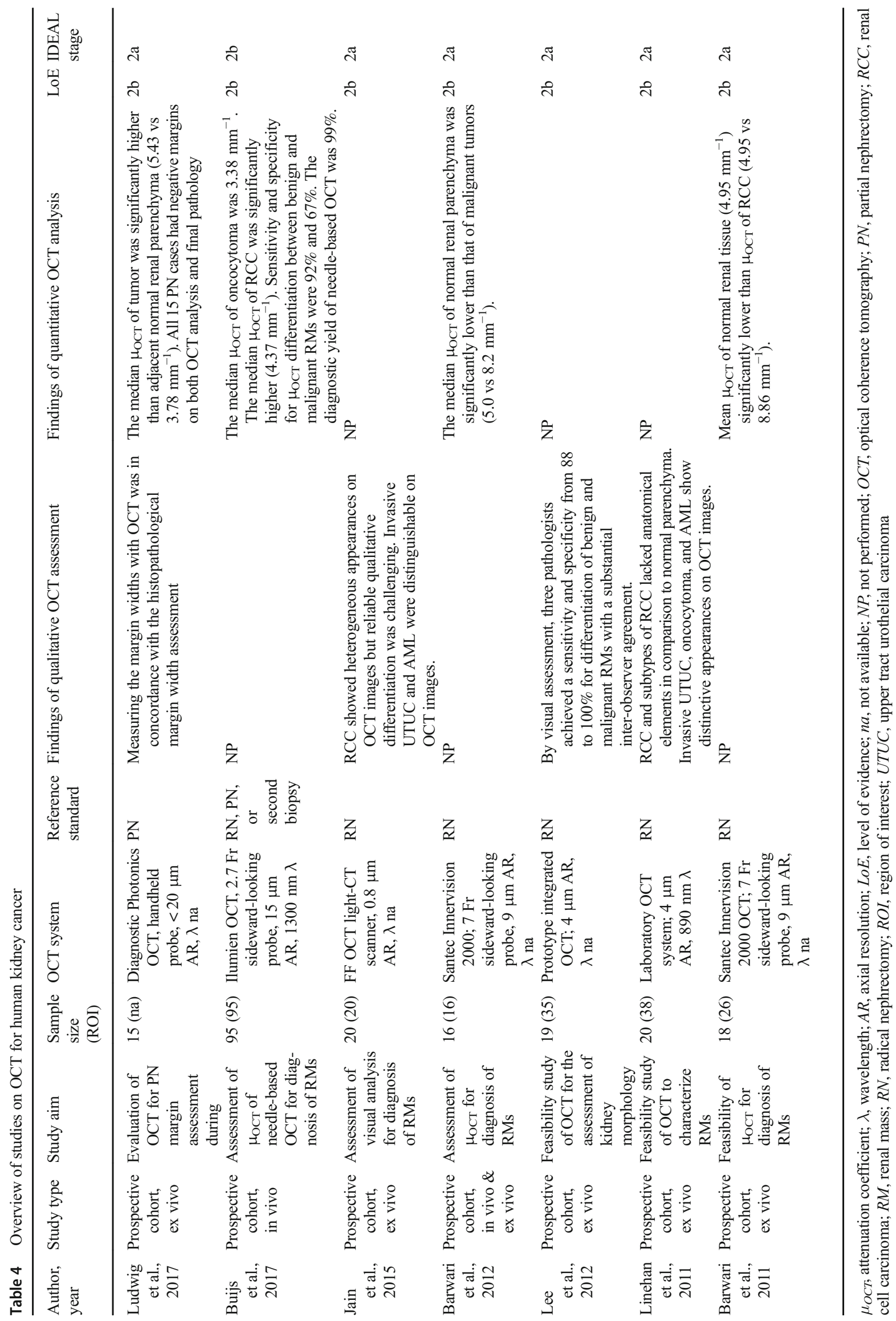



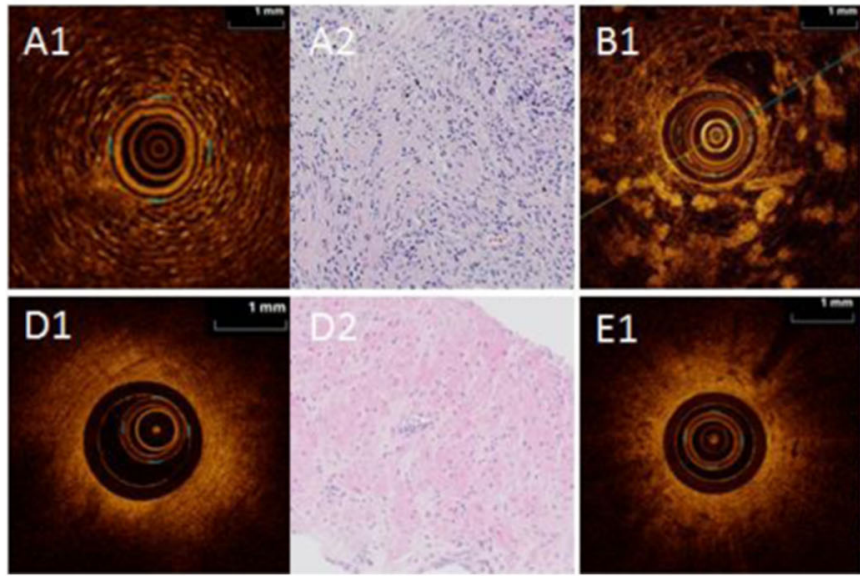

Fig. 4 Needle-based OCT brightness scans \& histopathology of renal tissue and prostate tissue. Legend: A1 +2) In vivo OCT brightness scan $\&$ histopathology of renal angiomyolipomas. B1 +2) In vivo OCT brightness scan \& histopathology of renal oncocytoma. $\mathrm{C} 1+2$ ) In vivo OCT brightness scan \& histopathology of clear cell RCC. D1 +2) Ex

\section{Kidney Cancer}

Throughout the past decades, we have witnessed an increase in kidney cancer, mostly at the expenses of small renal masses (SRM, $<4 \mathrm{~cm}$ ) [37]. About $90 \%$ of all kidney cancers are renal cell carcinomas (RCC), arising from the renal parenchyma. Multiple subtypes with heterogeneous clinical behavior can be identified by histo-morphologic features, microanatomic origin, and molecular alterations [38]. Clear cell RCC (ccRCC) is the most common subtype accounting for $75-80 \%$ of all RCCs. Its characteristic clear cell appearance is caused by the lipid and glycogen-rich cytoplasm [14]. Papillary RCC (pRCC) with a tubulopapillary architecture and chromophobe RCC (chRCC) are found in 10\% and 5\% of RCC patients, respectively [39]. Other more rare RCC subtypes, invasive UTUC, and benign tumors may also be the underlying pathology of renal masses.

Analysis of resected renal masses revealed $17-40 \%$ of benign pathology, mostly angiomyolipomas and oncocytomas [40]. This implies a clinically significant issue of preoperative misclassification [40]. As benign RM and cT1 RCC qualify for nephron-sparing treatment, preoperative renal mass biopsies (RMB) are gaining interest in the diagnostic algorithm. However, while accurate in terms of histologic reliability, RMB have a non-diagnostic rate of up to $23 \%$, which is negatively correlated with RM size [41, 42]. This shortcoming highlights the need for a test with a high diagnostic yield and accuracy to avoid unnecessary treatment or repeated biopsies.

Based on the systematic search, 9 relevant articles were identified, of which 2 had overlapping populations (Table 4) [34, 35, 43-47].

In the first studies, qualitative assessment of ex vivo OCT images for the diagnosis of RCC was challenging because of
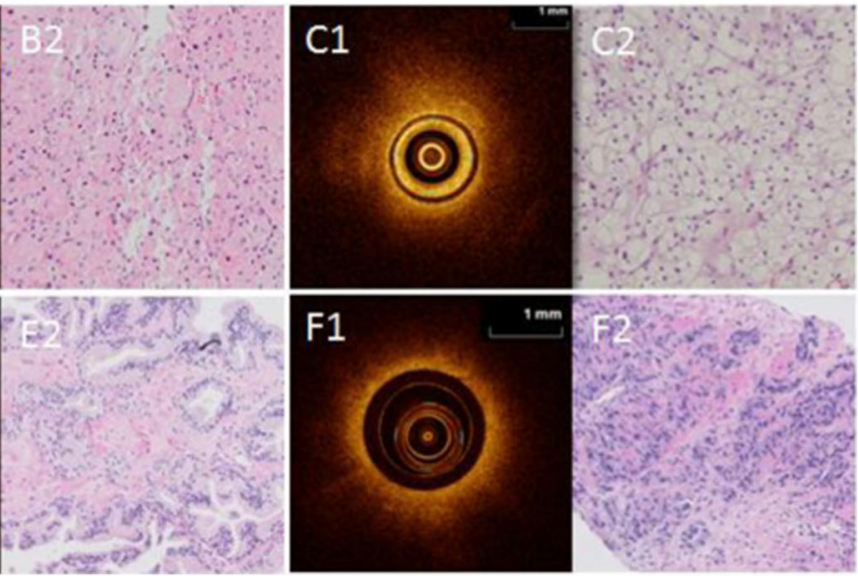

vivo OCT brightness scan \& histopathology of prostate stroma. E1 + 2) Ex vivo OCT brightness scan \& histopathology of benign glandular prostate. F1 + 2) Ex vivo OCT brightness scan \& histopathology of prostate cancer Gleason $4+4$

the heterogeneous appearance of RCC and the lack of distinctive OCT features [34, 35, 44]. Qualitative differentiation was only feasible in AML, oncocytomas, and invasive UTUC, where microarchitectural changes were recognizable [34, 35]. AML showed characteristic features of fat, which appeared as hypodense areas (Fig. 4). Oncocytomas demonstrated cystic areas and lobulated structures (Fig. 4) [34, 35]. In another study, qualitative OCT image assessment by three independent observers yielded a range in sensitivity and specificity from 88 to $100 \%$ for the differentiation of oncocytomas from RCCs [44].

Also, quantitative $\mu_{\mathrm{OCT}}$ analysis of OCT images, which were acquired during laparoscopy or percutaneous needlebased imaging, has been investigated for RCC diagnosis. Studies have shown that the $\mu_{\mathrm{OCT}}$ of RCC was significantly higher than normal renal parenchyma $[43,45,46]$. Buijs et al. investigated the diagnostic accuracy and yield of RMBs and concomitant in vivo percutaneous needle-based OCT imaging with sideward-looking probes in comparison to the histopathology of the resected specimen [46]. In their interim analysis cohort of 95 patients, $\mu_{\mathrm{OCT}}$ analysis from percutaneous needle-based OCT led to a diagnostic yield of 99\%, compared to a 79\% diagnostic yield for conventional RMBs. For differentiation between benign and malignant RMs, $\mu_{\mathrm{OCT}}$ showed a sensitivity of $91 \%$ and a specificity of $56 \%$. For the differentiation of RCC from oncocytoma, a sensitivity of $92 \%$ and a specificity of $67 \%$ were reported [46]. Since RMB is accompanied with a high non-diagnostic rate in smaller tumors, authors suggest that percutaneous needle-based OCT can potentially function as an add-on test or even as a replacement test in this niche of non-diagnostic cases.

Quantitative $\mu_{\mathrm{OCT}}$ analysis has also been evaluated for ex vivo assessment of surgical margins during partial nephrectomies. Authors demonstrated a high accuracy for identifying 


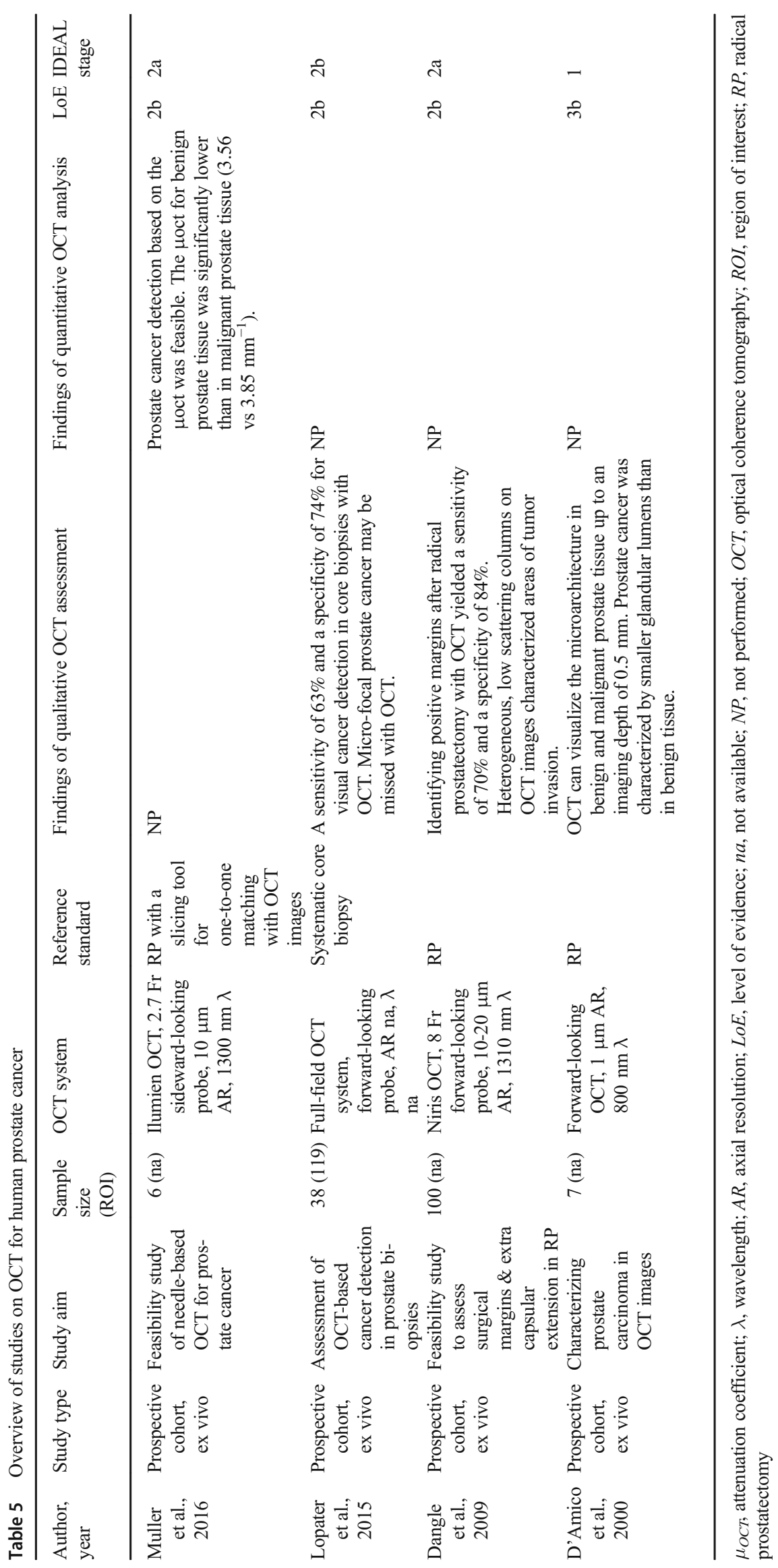


positive margins (sensitivity and specificity both $100 \%$ ), although the value was limited by a small sample size [47].

As such, quantitative $\mu_{\mathrm{OCT}}$ analysis for renal mass diagnosis has diagnostic potential. OCT adjunct to RMBs may enhance the diagnostic yield to improve the diagnostic pathway, with a possible "best benefit trade-off" in SRMs. The literature on OCT is still limited to LoE $2 b$ at IDEAL stage $2 b$ but respectable clinical cohort samples have been investigated.

\section{Prostate Cancer}

Prostate cancer (PC) is the most common cancer in men [48]. In $95 \%$ of the cases, $\mathrm{PC}$ is an adenocarcinoma. Other types of $\mathrm{PC}$ are small cell carcinomas, urothelial carcinomas, squamous, or basal cell carcinomas [14]. In the normal prostate gland, non-glandular and glandular tissues are interbred. Normal glandular tissue consists of organized stroma with smooth muscle fibers and well-organized glandular acini and ducts. Normal acini and ducts share a well-established microarchitecture of secretory, basal, and neuro-endocrine cells. Adenocarcinomas originate in $80 \%$ of the cases from acini or ducts [14]. Malignancy is characterized by a tendency towards disorganization, loss of architecture, and lack of basal cells. The Gleason-score and the corresponding grade groups are used to evaluate the grade of malignancy based on the architectural and morphologic alterations [49]. Prostate biopsies are the reference standard for PC diagnosis. However, the accuracy of tumor localization and demarcation of the current diagnostic approach is limited due to the multifocal nature of PC. Especially in the scope of focal therapies, exact identification of prostate cancer foci is required, driving the interest in new imaging modalities.

Six relevant articles on OCT in PC were identified with the systematic search, of which 3 use the same overlapping population (Table 5) $[8,50-52]$. The first OCT on human prostates was performed in an ex vivo study in 2000 [50]. OCT allowed demarcation of the prostatic microarchitecture $[50,52]$. Visualization of irregular gland contours, the infiltration of benign glands, or the visualization of cribriform patterns was the characteristic for PC on OCT images, demonstrating a sensitivity and specificity of $63 \%$ and $74 \%$, respectively [47]. However, micro-focal PC may be missed with OCT, although the clinical implication of these foci is unknown [52].

In 2016, the feasibility of quantitative $\mu_{\mathrm{OCT}}$-based PC diagnosis for potential percutaneous needle-based OCT of PC was investigated in prostatectomy specimen with sidewardlooking OCT probes in a needle-based fashion [8]. In this study, a customized tool for histopathology slicing was used for exact co-localization of the histopathology with OCT images (Fig. 4). Despite the limited sample size, the $\mu_{\mathrm{OCT}}$ in PC was significantly higher than in benign prostate tissue [8].

OCT was also investigated for the assessment of surgical margins after robotic prostatectomy in 100 patients with a 
forward-looking OCT device [51]. In this study, OCT-based predictions for the assessment of surgical margins were compared to the histopathology of the radical prostatectomy, yielding a sensitivity of $70 \%$ and a specificity of $84 \%$ [51]. OCT characteristics for positive margins were seen as heterogeneous columns of low signal intensity extending from the subepithelium to the surface of the serosa.

On balance, OCT has reached LoE $2 b$ at an IDEAL stage $2 \mathrm{a}$ in ex vivo studies, where visual assessment of OCT images and quantitative $\mu_{\mathrm{OCT}}$ analysis allow for PC identification [12]. Yet, translation to in vivo studies for PC diagnosis is lacking, possibly because the additional value of OCT for $\mathrm{PC}$ diagnosis may be marginal when considering the improvements of radiology-guided biopsies. A possible role for OCT in PC might be intraoperative assessment of surgical margins during radical surgery.

\section{Testicular Cancer}

Testicular cancer is the most prevalent solid cancer in young men. In $95 \%$ of the cases, testicular cancers are germ cell tumors, mostly seminomas and non-seminomas [14]. Ultrasound of the scrotum is the index test for initial diagnosis. In case of suspicious tumors, inguinal orchiectomy is diagnostic and therapeutic. Testicular biopsies are not considered in the presence of a normal contralateral case due to the risk of tumor seeding. According to our systematic search, OCT has not been investigated in testicular cancer. A hypothetical use of OCT in testicular tumors is the perioperative assessment of resection margins in partial orchiectomy.

\section{Penile Cancer}

Penile cancer $(\mathrm{PeC})$ is a rare disease in the Western World. It usually arises from malignancy of the epithelium of the glans or the prepuce. $\mathrm{PeC}$ is almost exclusively squamous cell carcinomas (SCC), although it may exhibit different morphologies. $\mathrm{PeC}$ presents as superficial horizontal growth, superficial exophytic growth, or invasive growth into deeper tissue layers [14]. SCC may be preceded by penile intraepithelial neoplasia (PIN). This pre-malignancy is characterized by a disorganized basal layer of the epithelium [14]. Punch biopsies are the reference standard for diagnosis.

Only 2 relevant articles were identified from the systematic search. A case report described the first use of OCT in premalignant penile lesions. The continuous dermo-epidermal junction zone of the superficial premalignant lesion was visualized and the local chemotherapy response was monitored [53]. A prospective cohort study with LoE $2 \mathrm{~b}$ at IDEAL stage $2 \mathrm{a}$ evaluated the use of OCT for the diagnosis of suspicious penile lesions (Table 6). OCT images of suspicious penile lesions were compared to histopathology of punch biopsies in 18 patients. Besides qualitative assessment of the integrity of tissue layers, quantification of the epidermal thickness and $\mu_{\mathrm{OCT}}$ analysis enabled PeC diagnosis (Fig. 3) [54]. Despite the limited evidence of this single study of $2 b$ LoE, OCT seems to have a promising diagnostic potential with a high clinical practical value for $\mathrm{PeC}$ and $\mathrm{PIN}$.

\section{Discussion}

With regard to the diagnostic potential of OCT in urologic oncology, the present appraisal on the current state of development of OCT shows an overall $\mathrm{LoE} 2 \mathrm{~b}$ and up to $2 \mathrm{a}-2 \mathrm{~b}$ IDEAL stages for all major urologic cancers with the exception of testis cancer. Overall, the current evidence indicates that OCT holds the potential as a replacement or add-on test for the diagnostic pathways in BC, UTUC, RCC, and $\mathrm{PeC}$. However, the setting is still exploratory as studies are predominantly single-center studies with restricted and heterogeneous samples, OCT methodology and technologic application. In some uro-oncological diseases, the technical level has not yet met all clinical requirements, and optimized OCT systems for urologic applications are still lacking. Nevertheless, in the light of some promising results and potential clinical practicality, further research should be fueled on OCT in most urologic oncology conditions. Future research and clinical implementation of OCT will eventually depend on thorough appraisal of the potential diagnostic gains, clinical availability, and costs in comparison with the index tests. Notably, we should catch the wave to combine different optical imaging techniques for a multimodal optical biopsy approach. Multimodal optical assessment, especially in combination with computer-aided diagnosis, could boost the additional diagnostic value of the new techniques with regard to the conventional diagnostic paradigms.

In $\mathrm{BC}$, transurethral resection is concomitantly diagnostic and therapeutic. As such, OCT may only be of an additional value during cystoscopy to provide histologic certitude for discharge, continuing routine follow-up, expectative policy, or outpatient laser vaporization of low-risk BC. However, the current state of development of OCT is hampered by the lack of a commercially available forward-looking probe.

In UTUC, the potential of OCT as an add-on or even replacement test for ureteroscopic biopsies seems alluring. OCT holds a high clinical and practical value for UTUC diagnosis because of its real-time character and the limited diagnostic yield and clinical burden of ureteroscopic biopsies. Especially, quantitative tumor grade differentiation could provide practical and objective intraoperative risk-stratification for adequate selection and immediate ureteroscopic treatment. Therefore, validation studies and phase III trials as well as technical development of a combined sideward- and forward-looking probe should be encouraged. Yet, the cost-effectiveness may be at risk as UTUC is a rare disease. 
Within the scope of the ongoing discussion on the role of RMB, especially in SRMs, OCT could be applied as an addon test to improve the diagnostic pathway. Further research to validate quantitative outcomes for $\mu_{\mathrm{OCT}}$-based diagnosis should be undertaken. Again, one should carefully balance the value of this add-on benefit versus the additional costs. Moreover, OCT could be used for intraoperative assessment of surgical margins in partial nephrectomies.

In $\mathrm{PeC}$, OCT could serve as a non-invasive replacement test for punch biopsies of suspicious penile lesions. Furthermore, OCT might even enable monitoring of the topical treatment response in PIN. Despite the low incidence of $\mathrm{PeC}$, further research should be stimulated to evaluate its diagnostic value. In view of the frequent centralized care of $\mathrm{PeC}$ and the use of re-usable handheld OCT devices, the costeffectiveness of OCT for $\mathrm{PeC}$ could be reasonable.

The role of OCT for PC diagnosis or image guidance adjunct for prostate biopsies seems limited in an additional diagnostic value. The combination of radiologic imaging with systematic and targeted biopsies represents a fierce competitor for optical imaging in PC diagnosis [55]. Yet, OCT could provide real-time histologic information. However, translation to in vivo diagnostic studies is lacking. Only one in vivo study for OCT-based assessment of resection margins in prostatectomies has been performed. Future research should define the role of OCT in PC.

At present, no OCT information is available for the diagnosis of testicular cancer. Because percutaneous diagnostic biopsy is not indicated, it is likely that the role of OCT will be limited at the most to perioperative assessment of the surgical margins during partial orchiectomy.

Overall, the strength of this comprehensive review is the systematic elaboration of the current state of development of OCT in all major uro-oncological diseases. However, the lack of high-level evidence, as well as the heterogeneity of study populations and technical data, limits the feasibility of a sound systematic review. Hence, conclusions are based on the first stages of the evaluation of a new technology. However, a thorough evaluation should be mandatory before clinical implementation. Moreover, early identification of conditions in which OCT may be most beneficial may stimulate and catalyze future developments. As such, this review will guide further translational research towards the implementation of OCT into uro-oncological practice.

Author Contribution J.E. Freund: Project development, data collection and management, manuscript writing

M. Buijs: Data collection, manuscript writing

C.D. Savci-Heijink: Project development, manuscript editing

D.M. de Bruin: Data collection, manuscript editing

J.J. de la Rosette: Project development, manuscript editing

T.G. van Leeuwen: Project development, manuscript editing

M.P. Laguna: Project development, manuscript editing

\section{Compliance with Ethical Standards}

Conflicts of Interest The authors declare that they have no conflict of interest.

Ethical Approval This article does not contain any studies with human participants performed by any of the authors.

\section{Appendix 1}

An individual search was performed for each organ in Pubmed and Embase for English and German articles up to December 2017. For each search, the key terms for OCT $\{\mathrm{OR}\}$ were combined $\{\mathrm{AND}\}$ with organ-specific key terms $\{\mathrm{OR}\}$.

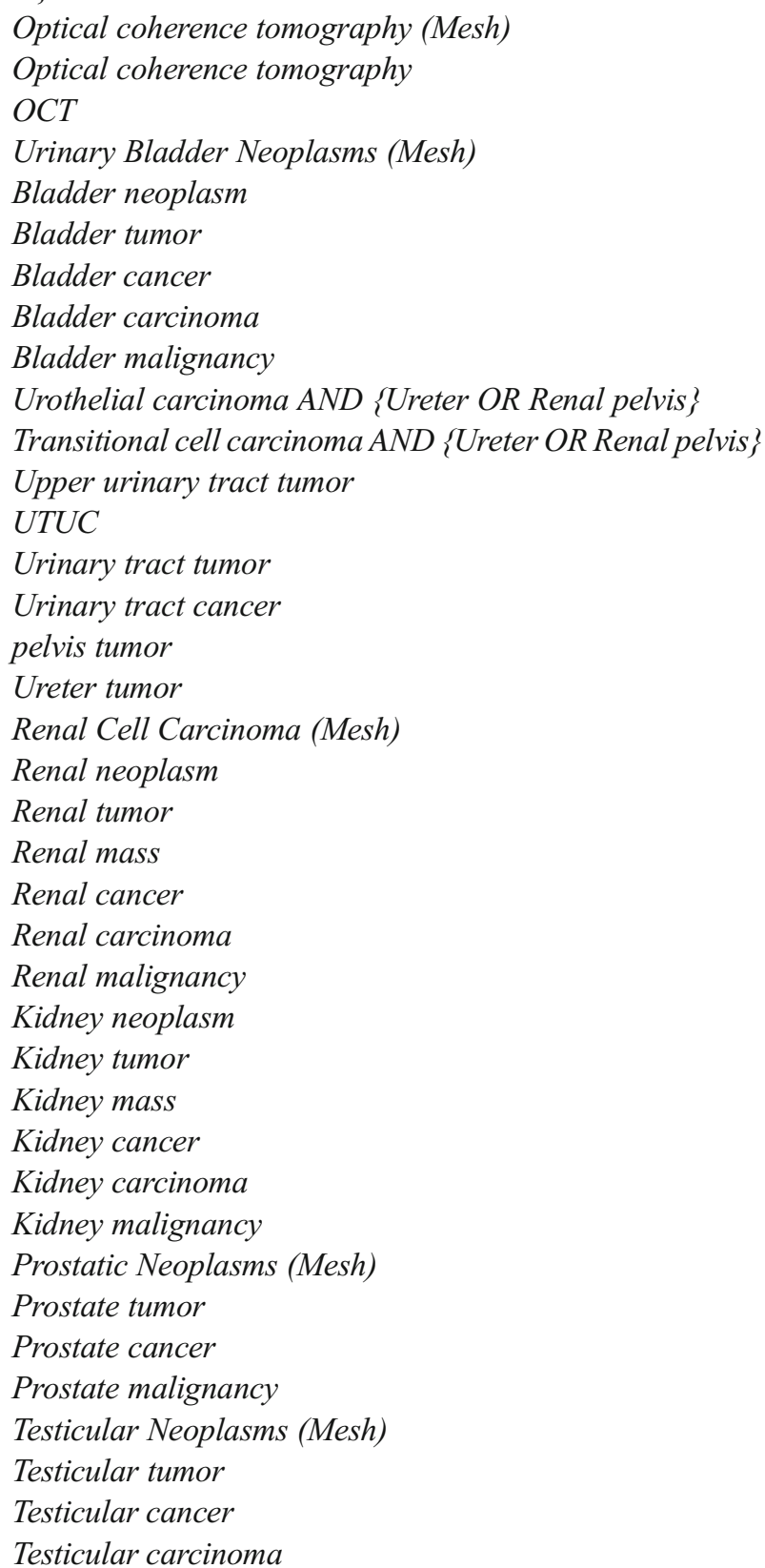


Testicular malignancy

Testis neoplasm

Testis tumor

Testis cancer

Testis carcinoma

Testis malignancy

Penile Neoplasms (Mesh)

Penile tumor

Penile cancer

Penile carcinoma

Penile malignancy

Penis neoplasm

Penis tumor

Penis cancer

Penis carcinoma

Penis malignancy

Flow diagram for study selection:

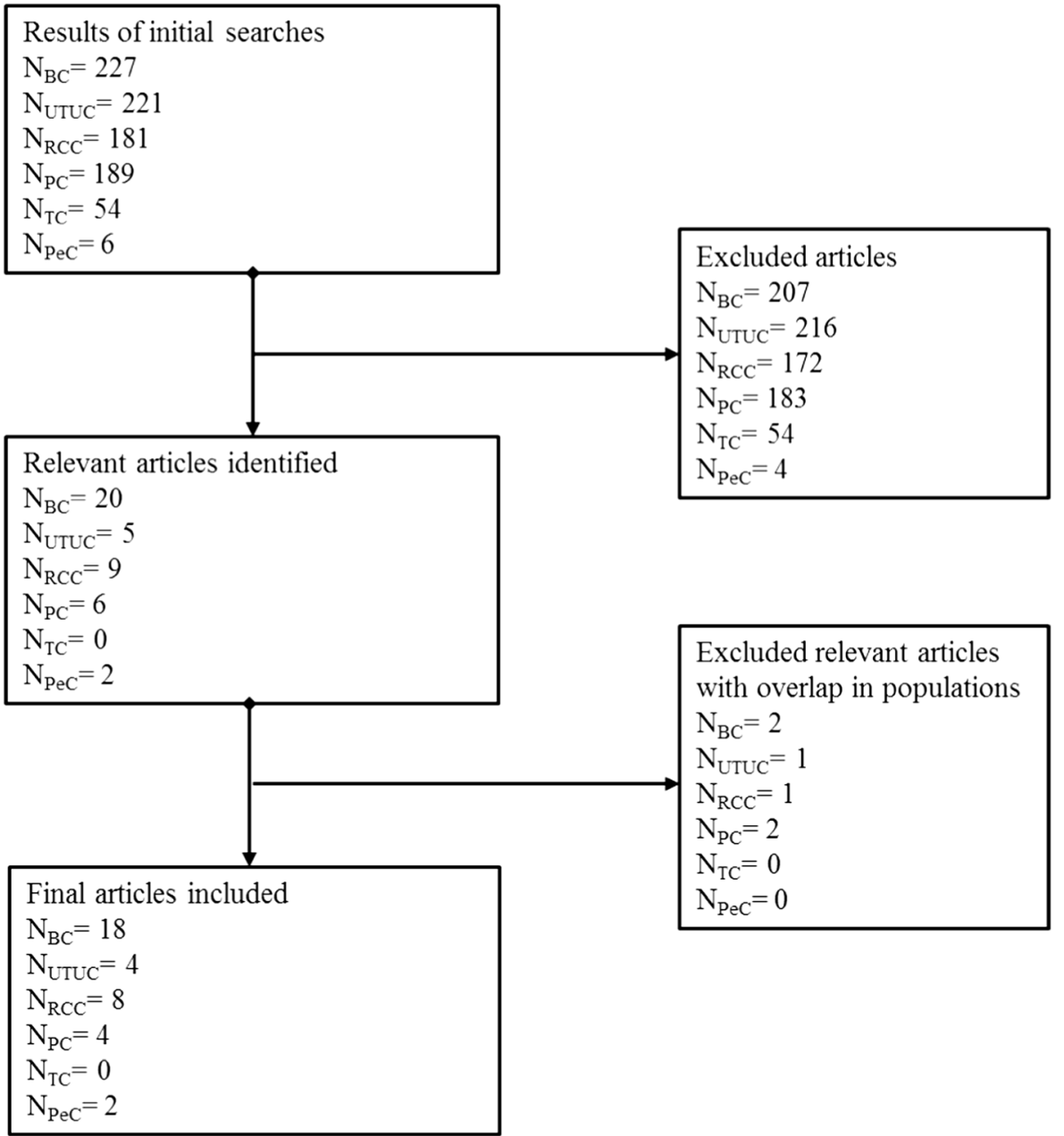

Legend: $B C$, bladder cancer; $U T U C$, upper tract urothelial carcinoma; $R C C$, renal cell carcinoma; $P C$, prostate cancer; $T C$, testicular cancer; $\mathrm{PeC}$, penile cancer 
Open Access This article is distributed under the terms of the Creative Commons Attribution 4.0 International License (http:// creativecommons.org/licenses/by/4.0/), which permits unrestricted use, distribution, and reproduction in any medium, provided you give appropriate credit to the original author(s) and the source, provide a link to the Creative Commons license, and indicate if changes were made.

\section{References}

1. Sergeev A, Gelikonov V, Gelikonov G, Feldchtein F, Kuranov R, Gladkova N, et al. In vivo endoscopic OCT imaging of precancer and cancer states of human mucosa. Opt Express. 1997;1(13):43240.

2. Xie T, Zeidel M, Pan Y. Detection of tumorigenesis in urinary bladder with optical coherence tomography: optical characterization of morphological changes. Opt Express. 2002;10(24):143143.

3. Lingley-Papadopoulos C, Loew MH, Zara JM. Wavelet analysis enables system-independent texture analysis of optical coherence tomography images. J Biomed Opt. 2009;14(4):044010.

4. Schmitt JM, Xiang SH, Yung KM. Speckle in optical coherence tomography. J Biomed Opt. 1999;4(1):95-105.

5. Kiseleva EB, Gubarkova EV, Dudenkova VV, Timashev PS, Kotova SL, Timofeeva LB, et al. Complementary study of collagen state in bladder diseases using cross-polarization optical coherence tomography, nonlinear and atomic force microscopy. Sovrem Tehnol v Med. 2017;9(1):7.

6. Kiseleva E, Kirillin M, Feldchtein F, Vitkin A, Sergeeva E, Zagaynova E, et al. Differential diagnosis of human bladder mucosa pathologies in vivo with cross-polarization optical coherence tomography. Biomed Opt Express. 2015;6:1464-76.

7. Cauberg EC, de Bruin DM, Faber DJ, de Reijke TM, Visser M, de la Rosette JJ, et al. Quantitative measurement of attenuation coefficients of bladder biopsies using optical coherence tomography for grading urothelial carcinoma of the bladder. J Biomed Opt. 2010;15:66013.

8. Muller BG, de Bruin DM, Brandt MJ, van den Bos W, van Huystee $\mathrm{S}$, Faber DJ, et al. Prostate cancer diagnosis by optical coherence tomography: first results from a needle based optical platform for tissue sampling. J Biophotonics. 2016;9(5):490-8.

9. Bus MTJ, de Bruin DM, Faber DJ, Kamphuis GM, Zondervan PJ, Laguna-Pes MP, et al. Optical coherence tomography as a tool for in vivo staging and grading of upper urinary tract urothelial carcinoma: a study of diagnostic accuracy. J Urol. 2016;196(6):1749-55.

10. Phillips B, Ball C, Badenoch D, Straus S, Haynes B, Dawes M. Oxford centre for evidence-based medicine levels of evidence. BJU Int. 2009; 104:1825.

11. Pennell CP, Hirst AD, Campbell WB, Sood A, Agha RA, Barkun JST, et al. Practical guide to the idea, development and exploration stages of the IDEAL framework and recommendations. Br J Surg. 2016;103(5):607-15.

12. Babjuk M, Böhle A, Burger M, Compérat E, Kaasinen E, Palou J, et al. EAU guidelines on bladder cancer. Eur Urol. 2017:1-45.

13. Keshtkar A, Keshtkar A, Lawford P. Cellular morphological parameters of the human urinary bladder (malignant and normal). Int $\mathrm{J}$ Exp Pathol. 2007;88(3):185-90.

14. Paner GP. Pathology for urologists [Internet]. g. 2017 [cited 2017 Dec 16]. Available from:e https://www.auanet.org/education/ modules/pathology/index.cfm

15. Al-Hussain T, Chaux A, Gaumann A, Levy G. PathologyOutlines. com [Internet]. 2016 [cited 2017 Dec 16]. Available from: http:// pathologyoutlines.com/bladder.html
16. Cina SJ, Epstein JI, Endrizzi JM, Harmon WJ, Seay TM, Schoenberg MP. Correlation of cystoscopic impression with histologic diagnosis of biopsy specimens of the bladder. Hum Pathol. 2001;32(6):630-7.

17. Zagaynova E, Gladkova N, Shakhova N, Gelikonov G, Gelikonov $\mathrm{V}$. Endoscopic OCT with forward-looking probe: clinical studies in urology and gastroenterology. J Biophotonics. 2008;1:114-28.

18. Sengottayan VK, Vasudeva P, Dalela D. Intravesical real-time imaging and staging of bladder cancer: use of optical coherence tomography. Indian J Urol. 2008;24:592-3.

19. Ren H, Waltzer WC, Bhalla R, Liu J, Yuan Z, Lee CS, et al. Diagnosis of bladder cancer with microelectromechanical systems-based cystoscopic optical coherence tomography. Urology. 2009;74:1351-7.

20. Schmidbauer J, Remzi M, Klatte T, Waldert M, Mauermann J, Susani M, et al. Fluorescence cystoscopy with high-resolution optical coherence tomography imaging as an adjunct reduces falsepositive findings in the diagnosis of urothelial carcinoma of the bladder. Eur Urol. 2009;56:914-9.

21. Karl A, Stepp H, Willmann E, Buchner A, Hocaoglu Y, Stief C, et al. Optical coherence tomography for bladder cancer - ready as a surrogate for optical biopsy? Results of a prospective mono-centre study. Eur J Med Res. 2010;15(3):131-4.

22. Gladkova N, Streltsova O, Zagaynova E, Kiseleva E, Gelikonov V, Gelikonov G, et al. Cross-polarization optical coherence tomography for early bladder-cancer detection: statistical study. J Biophotonics. 2011;4:519-32.

23. Gladkova N, Kiseleva E, Streltsova O, Prodanets N, Snopova L, Karabut M, et al. Combined use of fluorescence cystoscopy and cross-polarization OCT for diagnosis of bladder cancer and correlation with immunohistochemical markers. J Biophotonics. 2013;6: 687-98.

24. Jesser CA, Boppart SA, Pitris C, Stamper DL, Nielsen GP, Brezinski ME, et al. High resolution imaging of transitional cell carcinoma with optical coherence tomography: feasibility for the evaluation of bladder pathology. Br J Radiol. 1999;72:1170-6.

25. Tearney GJ, Brezinski ME, Southern JF, Bouma BE, Boppart SA, Fujimoto JG. Optical biopsy in human urologic tissue using optical coherence tomography. J Urol. 1997;157(5):1915-9.

26. Manyak MJ, Gladkova ND, Makari JH, Schwartz AM, Zagaynova EV, Zolfaghari L, et al. Evaluation of superficial bladder transitional-cell carcinoma by optical coherence tomography. J Endourol. 2005;19:570-4.

27. Daniltchenko D, König F, Lankenau E, Sachs M, Kristiansen G, Huettmann $G$, et al. Anwendung der optischen Kohärenztomographie (OCT) bei der Darstellung von Urothelerkrankungen der Harnblase. Radiologe. 2006;46(7):584-9.

28. Hermes B, Spoler F, Naami A, Bornemann J, Forst M, Grosse J, et al. Visualization of the basement membrane zone of the bladder by optical coherence tomography: feasibility of noninvasive evaluation of tumor invasion. Urology. 2008;72(3):677-81.

29. Goh AC, Tresser NJ, Shen SS, Lerner SP. Optical coherence tomography as an adjunct to white light cystoscopy for intravesical real-time imaging and staging of bladder cancer. Urology. 2008;72(1):133-7.

30. Rouprêt M, Babjuk M, Compérat E, Zigeuner R, Sylvester RJ, Burger M, et al. European association of urology guidelines on upper urinary tract urothelial carcinoma: 2017 update. Eur Urol. 2018;73(1):111-22.

31. Baard J, de Bruin DM, Zondervan PJ, Kamphuis G, de la Rosette J, Laguna MP. Diagnostic dilemmas in patients with upper tract urothelial carcinoma. Nat Rev Urol. 2017;14(3):181-91.

32. Cutress ML, Stewart GD, Zakikhani P, Phipps S, Thomas BG, Tolley DA. Ureteroscopic and percutaneous management of upper tract urothelial carcinoma (UTUC): systematic review. BJU Int. 2012;110(5):614-28. 
33. Ikeda M, Matsumoto K, Choi D, Nishi M, Fujita T, Ohbayashi K, et al. The impact of real-time $3 \mathrm{~d}$ imaging by ultra-high speed optical coherence tomography in urothelial carcinoma. BMC Urol. 2013;13:65.

34. Jain M, Robinson B, Salamoon B, Thouvenin O, Boccara C, Mukherjee S. Rapid evaluation of fresh ex vivo kidney tissue with full-field optical coherence tomography. J Pathol Inf. 2015;6:53.

35. Linehan JA, Bracamonte ER, Hariri LP, Sokoloff MH, Rice PS, Barton JK, et al. Feasibility of optical coherence tomography imaging to characterize renal neoplasms: limitations in resolution and depth of penetration. BJU Int. 2011;108(11):1820-4.

36. Mueller-Lisse UL, Bader M, Englram E, Stief C, Reiser MF, Mueller-Lisse UG. Catheter-based intraluminal optical coherence tomography of the normal human upper urinary tract in vivo: proof of concept and comparison with an ex-vivo porcine model. Bladder. 2016;3(1):21.

37. Siegel RL, Miller KD, Jemal A. Cancer statistics. CA Cancer J Clin. 2016;66(1):7-30.

38. Moch H, Cubilla AL, Humphrey PA, Reuter VE, Ulbright TM. The 2016 WHO classification of tumours of the urinary system and male genital organs - part a: renal, penile, and testicular tumours. Eur Urol. 2016;70(1):93-105.

39. Muglia VF, Prando A. Renal cell carcinoma: histological classification and correlation with imaging findings. Radiol Bras. 2015;48(3):166-74.

40. Johnson DC, Vukina J, Smith AB, Meyer AM, Wheeler SB, Kuo TM, et al. Preoperatively misclassified, surgically removed benign renal masses: a systematic review of surgical series and United States population level burden estimate. J Urol. 2015;193(1):30-5.

41. Prince J, Bultman E, Hinshaw L, Drewry A, Blute M, Best S, et al. Patient and tumor characteristics can predict nondiagnostic renal mass biopsy findings. J Urol. 2015;193(6):1899-904.

42. Patel HD, Johnson MH, Pierorazio PM, Sozio SM, Sharma R, Iyoha E, et al. Diagnostic accuracy and risks of biopsy in the diagnosis of a renal mass suspicious for localized renal cell carcinoma: systematic review of the literature. J Urol. 2016;195(2):1-8.

43. Barwari K, de Bruin DM, Cauberg ECC, Faber DJ, van Leeuwen TG, Wijkstra $\mathrm{H}$, et al. Advanced diagnostics in renal mass using optical coherence tomography: a preliminary report. J Endourol. 2011;25(2):311-5.

44. Lee HC, Zhou C, Cohen DW, Mondelblatt AE, Wang Y, Aguirre $\mathrm{AD}$, et al. Integrated optical coherence tomography and optical coherence microscopy imaging of ex vivo human renal tissues. J Urol. 2012;187:691-9.
45. Barwari K, De Bruin DM, Faber DJ, Van Leeuwen TG, De la Rosette JJ, Laguna MP. Differentiation between normal renal tissue and renal tumours using functional optical coherence tomography: a phase I in vivo human study. BJU Int. 2012:415-20.

46. Buijs M, Wagstaff PGK, de Bruin DM, Zondervan PJ, SavciHeijink CD, van Delden OM, et al. An in-vivo prospective study of the diagnostic yield and accuracy of optical biopsy compared with conventional renal mass biopsy for the diagnosis of renal cell carcinoma: the interim analysis. Eur Urol Focus. 2017. https://doi. org/10.1016/j.euf.2017.10.002.

47. Ludwig WW, Wobker SE, Ball MW, Zysk AM, Yemul KS, Pierorazio PM, et al. Margin assessment in renal surgery using a handheld optical coherence tomography probe. Urology. 2017;Mar(113):241-5.

48. Siegel R, Ma J, Zou Z, Jemal A. Cancer statistics, 2014. CA Cancer J Clin. 2014;64(1):9-29.

49. Epstein J, Egevad L, Amin M, Delahunt B, Srigley J, Humphrey P. The 2014 International Society of Urological Pathology (ISUP) consensus conference on Gleason grading of prostatic carcinoma: definition of grading patterns and proposal for a new grading system. Am J Surg Pathol. 2016;40(2):244-52.

50. D'Amico V, Weinstein M, Li X, Richie JP, Fujimoto J. Optical coherence tomography as a method for identifying benign and malignant microscopic structures in the prostate gland. Urology. 2000;55(5):783-7.

51. Dangle PP, Shah KK, Kaffenberger B, Patel VR. The use of high resolution optical coherence tomography to evaluate robotic radical prostatectomy specimens. Int Braz J Urol. 2009;35(3):344-53.

52. Lopater J, Colin P, Beuvon F, Sibony M, Dalimier E, Cornud F, et al. Real-time cancer diagnosis during prostate biopsy: ex vivo evaluation of full-field optical coherence tomography (FFOCT) imaging on biopsy cores. World J Urol. 2016;34(2):237-43.

53. Schmitz L, Bierhoff E, Dirschka T. Optical coherence tomography imaging of erythroplasia of Queyrat and treatment with imiquimod 5\% cream: a case report. Dermatology. 2014;228(1):24-6.

54. Wessels R, De Bruin DM, Faber DJ, Horenblas S, Van Rhijn BWG, Vincent $\mathrm{AD}$, et al. Optical coherence tomography accurately identifies patients with penile (pre) malignant lesions: a single center prospective study. Urol Ann. 2015;7:459-65.

55. Mottet N, Bellmunt J, Bolla M, Briers E, Cumberbatch MG, De Santis M, et al. EAU-ESTRO-SIOG guidelines on prostate cancer. Part 1: screening, diagnosis, and local treatment with curative intent. Eur Urol. 2017;71(4):618-29. 